\title{
Compreensão de frases gramaticais com nível de especificidade e esquematicidade por pessoas com Alzheimer: uma análise psicolinguística e cognitiva
}

\author{
Comprehension in grammatical sentences at the level of specificity and schematicity in \\ Alzheimer's disease: an analysis psycholinguistics and cognitive.
}

\section{Berla Moreira de Moraes}

\author{
Jan Edson Rodrigues Leite
}

Universidade Federal da Paraíba - UFPB - João Pessoa - Paraíba - Brasil

\begin{abstract}
Resumo: Esta pesquisa objetivou identificar se, na doença de Alzheimer, existe comprometimento na compreensão de frases gramaticais no nível de especificidade, por meio da técnica de leitura automonitorada. No intuito de atingir nossos objetivos e respondermos nossas hipóteses, empreendemos um experimento para analisar: o tempo de reação na leitura da frase, o tempo de reação para leitura da pergunta de compreensão e escolha da resposta, e o índice de acerto nas perguntas de compreensão por adultos jovens (AJ) e idosos saudáveis (IS) como grupos controle, e idosos com provável Alzheimer (IPAI/IPAM) como grupo caso, considerando frases no nível de especificidade e esquematicidade. Participaram da aplicação dos experimentos, 10 AJ, 10 IS e 10 IPAI/IPAM, totalizando uma amostra de 30 sujeitos. Os resultados apontam que a pessoa com Alzheimer apresenta desempenho inferior na compreensão da imagética convencional, em termos de índice de acertos e de tempo de resposta, quando comparados com idosos sem declínio cognitivo. Como resultado do experimento, com relação ao nível de Especificidade, as pessoas com Alzheimer demandam maior tempo na leitura e em dar respostas em frases de esquematicidade, nas quais também se observa maior índice de erro nas respostas. Confirmou-se então a hipótese de que a compreensão da imagética convencional em frases gramaticais no nível de especificidade, estão afetadas desde os estágios iniciais da doença de Alzheimer, e acreditamos que seja influenciada pelo declínio cognitivo progressivo da memória de trabalho, da velocidade de processamento, da tomada de decisão e da orientação temporal e espacial.
\end{abstract}

Palavras-chave: Compreensão da Linguagem. Nível de especificidade. Doença de Alzheimer.

\begin{abstract}
The present research aimed at identifying if there is any compromise regarding the comprehension in grammatical sentences at the level of specificity, through the self-paced reading technique, produced by people suffering from Alzheimer. With the objective of reaching our goals and finding answers to our hypotheses, one experiment was carried out to analyse: the time of reaction while reading the sentence, the time of reaction for reading the comprehension questions and choosing the best answer, and the score of right answers given by young adults (YA) and healthy old (HO) taken as groups of control and the old with likely Alzheimer (OLA) as case group, considering sentences: at the level of schematicity and specificity. $10 \mathrm{YA}, 10 \mathrm{HO}$ and 10 OLA took part in the experiments, totalling thirty participants. Results show that, when compared to the old without cognitive decline, people suffering from Alzheimer present inferior performance in comprehending conventional imagery when it comes to the rate of right answers and the time of response. As the result of the experiment, in relation to the level of specificity, people with Alzheimer need more time to read and give answers before schematic sentences, in which is also noticed the highest rate of wrong anwers. The hypothesis that the comprehension of conventional imagery in grammatical sentences at the level of specificity, is affected since the early stages of the Alzheimer disease was confirmed. We believe that this is influenced by the progressive cognitive decline of the working memory, by the speed of processing, by the decision making and also by the spacial and temporal orientation.
\end{abstract}

Keywords: Language Comprehension. Level of Specificity. Alzheimer Disease. 


\section{Introdução}

Uma expressão pode ser conceptualizada em diferentes níveis de especificidade e detalhe. Esta escolha depende do nível de especificidade com que se quer retratar uma cena, bem como do contexto discursivo e qual "propósito comunicativo em determinada situação" (FERRARI, 2011, P. 62).

Hierarquicamente, um item lexical pode ser mais esquemático (genérico) ou mais específico. Esta relação é representada por uma seta sólida $\left(\begin{array}{ll}A & B\end{array}\right)$, onde cada expressão é esquemática em relação às que se seguem (LANGACKER, 2008). Observemos os exemplos a seguir:

Vegetal $\longrightarrow$ Fruta $\longrightarrow$ Banana $\longrightarrow$ Banana prata Ex 1: Hierarquia do domínio esquemático ao específico.

Langacker (2008) refere que, ao analisarmos os nomes "vegetal" e "fruta", verifica-se que "fruta" representa de forma mais precisa a categoria de vegetais, dessa maneira, "banana" se torna mais específico que "fruta" e "banana prata" o mais específico desta hierarquia, considerando o exemplo acima demonstrado. Assim, considerando determinados contextos discursivos, pode-se dizer: "O idoso comeu uma fruta no lanche", cuja frase representa uma maior esquematicidade, porém também se pode dizer de forma mais específica: "O idoso comeu uma banana no lanche", ou então, com um nível de especificidade ainda maior: "O idoso comeu uma banana prata no lanche".

A estruturação das frases acima citadas exemplifica o que Ferrari (2011, P. 62) afirma: "operamos em níveis bastante diferentes por motivos distintos". A frase "O idoso comeu uma fruta no lanche" é esquemática, visto que a categoria fruta não é especificada na cena, podendo ser qualquer fruta, dentre as possibilidades de frutas existentes. Conseguimos retratar esta cena como sendo de um sujeito agente (o idoso) que exerceu uma função referente às suas necessidades básicas (comeu) um tipo de fruta que não é especificado. Esta cena, porém, pode ser retratada de formas mais específicas como na frase: "O idoso comeu uma banana no lanche".
Nesta frase, a categoria fruta é especificada, então se conhece que o idoso não comeu pera, maçã, mas sim uma banana. E esta ainda pode ser mais específica, como referindo o tipo de banana, no caso, comeu uma banana prata, mas poderia ter sido uma banana nanica, bem como uma banana machucada com algum ingrediente como aveia ou outro cereal. A referida autora ainda reforça que estas informações são importantes, dependendo do contexto discursivo e do propósito comunicativo desta situação, por exemplo, uma nutricionista que precisa saber se o tipo de fruta que o idoso comeu faz parte da dieta prescrita, dessa forma pode necessitar de uma informação mais específica, ou um familiar que precisa saber o que o idoso comeu no lanche, e o cuidador refere que foi uma fruta e esta informação é suficiente para o familiar.

Segundo Silva (2008), o âmbito de uma expressão compreende a totalidade dos domínios cognitivos que ela simboliza, e dos quais depende a sua caracterização. De acordo com Langacker (2008) isto se dá por que:

A esquematicidade é fundamental para a cognição e ocorre constantemente em todos os domínios de experiência em uso da fala, pois serve para captar o que é comum para certas experiências anteriores e aplicar a qualquer nova experiência exibindo a mesma configuração. A Gramática cognitiva afirma que todas as generalizações linguísticas surgem via esquematização de estruturas mais específicas (LANGACKER, 2008. p 56-57).

Lakoff (1987) refere que grande parte das palavras e dos conceitos designam categorias e explica que o processo de categorização humano:

\begin{abstract}
Não é um processo que deve ser estudado superficialmente. Não há nada mais básico do que a categorização para 0 nosso pensamento, percepção, ação e discurso. Cada vez que nós vemos algo como "um tipo" de coisa, por exemplo, uma árvore, nós estamos categorizando. A compreensão de como categorizamos é o ponto central para a compreensão de como nós pensamos, funcionamos e, consequentemente, um ponto central para a compreensão daquilo que nos faz humanos (LAKOFF, 1987, p.5).
\end{abstract}

Categorizamos em nível hierárquico, tendo um nível básico onde grande parte de nosso conhecimento 
é organizado, partindo para um nível mais esquemático/sobreordenado ou para um nível mais subordinado/específico (ROSCH; MERVIS, 1975).

Corroboramos com o pensamento de Rizzatti (2001) quando refere que a categoria básica:

É o nível mais inclusivo de categoria em que as formas dos objetos são parecidas e, consequentemente, mais facilmente reconhecidas; é também o nível privilegiado no desenvolvimento linguístico: o primeiro a ser nomeado, aprendido e a entrar no léxico da língua. Neste nível uma única imagem mental pode refletir a categoria inteira (RIZZATTI, 2001, p.18).

Segundo Lima (2010), quando nos deparamos em um evento comunicativo, as informações são estruturadas com base nas capacidades cognitivas que permeiam a categorização. As ideias, os conhecimentos, as categorias esquemáticas, básicas e/ou específicas são organizados em nossos sistemas de memória, mais especificamente, na memória semântica. Ocorre então um dinâmico processo de adição de novas informações que se somam às existentes formando e estruturando redes semânticas.

O processo de ativação dessas redes e de recuperação das informações nelas existentes depende do nível de habilidade cognitiva do indivíduo, visto que este pode estar em processo de deterioração cognitiva que interfere diretamente nas habilidades comunicativas.

$\mathrm{Na}$ doença de Alzheimer, as dificuldades nas funções cognitivas linguísticas, como a linguagem, e as dificuldades nas funções cognitivas não linguísticas, como a memória, habilidades visioespaciais, funções executivas, tomada de decisão, são considerados um dos principais sinais cognitivos que evoluem com a progressão da doença (ROBLES, AMOM E PEÑACASANOVA, 2002).

Estas dificuldades repercutem no prejuízo observado na compreensão da leitura textual, visto que o ato de ler exige várias habilidades linguísticas, como decodificação da linguagem impressa, compreensão das palavras informadas (RINALDI, 2008).

Diante deste contexto, para desenvolver esta pesquisa empírica, orientamo-nos numa perspectiva psicolinguística experimental que tem como objetivo básico descrever e analisar a maneira como o ser humano compreende e produz linguagem, observando fenômenos linguísticos relacionados ao processamento da linguagem. Ou seja, esses fenômenos são tratados e focalizados do ponto de vista de sua execução pelos falantes/ouvintes a partir de seu aparato perceptual/articulatório e de seus sistemas de memória (LEITÃO, 2008).

\section{Metodologia}

Trata-se de uma pesquisa experimental, exploratória, transversal, do tipo caso-controle. A amostra foi composta por participantes voluntários: 10 pessoas com diagnóstico de doença de Alzheimer em fase inicial e moderada que frequentam o grupo de estimulação cognitiva, e grupo controle composto por 10 idosos saudáveis que frequentam o grupo de atividade física e 10 adultos jovens acadêmicos.

O projeto envolvendo seres humanos ao qual esta pesquisa é vinculada foi cadastrado na Plataforma Brasil e aprovado no Comitê de Ética em Pesquisa do Centro de Ciências da Saúde da Universidade Federal da Paraíba (Protocolo de aprovação n 228.544, em 11/12/2012). Todos os procedimentos propostos aos voluntários que participaram da pesquisa estão de acordo com a Resolução 196/96 e a Resolução $466 / 2012$

\section{Processo de elaboração das frases de especificidade e esquematicidade:}

O Procedimento utilizado para elaboração das frases do experimento consistiu dos seguintes passos:

- A escolha do tipo de estrutura sintática comum a todas as frases: optou-se por uma frase canônica: SVO (Sujeito + Verbo + Objeto) do tipo transitiva direta e indireta, com complementos verbais da oração: objeto direto e objeto indireto. Verbos transitivos diretos e indiretos, conjugação verbal na terceira pessoa do singular do pretérito perfeito do indicativo.

- Diante desta escolha, pode-se determinar da extensão da frase, controlando o número de palavras, 
a frequência de cada palavra crítica na língua portuguesa (português brasileiro).

- A palavra crítica correspondia ao nível de especificidade, que estava sempre na posição de objeto direto (na quinta posição na estrutura da frase).

- Diante das frases elaboradas com o nível de especificidade, pensou-se em elaborar frases que permitissem um confronto: a esquematicidade, ou seja, as mesmas frases elaboradas com palavras críticas contendo o nível de especificidade, também fossem elaboradas substituindo a palavra crítica específica, por uma palavra crítica do mesmo domínio sendo mais esquemática.

Ex 2: A esposa deixou a sopa no fogão. (frase com nível de especificidade)

Ex 3: A esposa deixou a refeição no fogão.(frase esquemática).

- Para cada frase foi elaborada uma pergunta de compreensão com duas opções de resposta. Ex 4: O que a esposa deixou no fogão? ( ) sopa ( ) refeição

- As frases foram submetidas a um teste de plausibilidade e analisadas estatisticamente.

\section{Desenho do experimento:}

O experimento tinha como objetivo verificar a influência do input linguístico (frase) na compreensão da imagética convencional no nível de especificidade em frases gramaticais por pessoas com Alzheimer.

Como variável independente, consideramos 0 Input linguístico (frase de especificidade e frase de esquematicidade). Para as variáveis dependentes, consideramos o tempo de leitura da frase (em milésimos de segundos); o tempo de reação entre o final da leitura da pergunta interpretativa e a resposta (em milésimos de segundos); e o índice de acertos das perguntas interpretativas.

A hipótese experimental era que o tempo de leitura e o tempo de resposta de pessoas com Alzheimer nos estímulos é superior ao do grupo controle. E que a pessoa com Alzheimer compreende as sentenças de nível de especificidade e tem índices de acertos nas perguntas interpretativas inferior ao grupo controle.
O material experimental para leitura automonitorada consistiu de 24 frases elegíveis a partir do teste de plausibilidade considerando o nível de especificidade/esquematicidade, seguidas por pergunta interpretativa com duas opções de respostas, acrescidas de 24 frases distratoras totalizando 48 frases.

O que a esposa deixou no fogão?

A esposa deixou a sopa no fogão

Toque aqui para passar

Quadro 1: Exemplo de frase do tipo Nível de Especificidade (lado esquerdo), a pergunta de compreensão e as opções de resposta (lado direito) elaborados no software Paradigm.

Nos experimentos de leitura automonitorada utilizou-se um Ipad 2 com tela touch screen, programado através do software Paradigm, versão v2. 3. 29 (x64), que permitiu projetar e monitorar experimentos psicolinguísticos, controlando os índices de acertos e o tempo de reação em milésimos de segundos.

O procedimento para a aplicação do experimento consistiu dos seguintes passos: o experimento foi aplicado individualmente com cada participante voluntário. No primeiro momento, iniciamos com 0 teste de preparação para o experimento. Neste, o participante leu as instruções iniciais e realizou uma prática do teste composta de 05 frases similares a fim de não restar dúvidas acerca do experimento. Garantida a correta compreensão da tarefa pelos voluntários, o experimento foi iniciado. A tarefa consistiu de ler frase na tela do Ipad no tempo necessário para compreensão, sem delimitação do tempo. Após o término da leitura de cada frase, o voluntário pressionava uma seta, que fazia aparecer uma nova tela com uma pergunta de compreensão à frase e as duas opções de resposta, também sem 
delimitação do tempo para leitura e escolha. A pergunta deveria ser escolhida, pressionando uma das duas opções na tela do Ipad. A resposta marcada foi gravada, registrando erro ou acerto e o tempo em milésimos de segundos. A operação foi repetida até concluir o todo experimento, e, ao final, aparecia uma tela com a expressão "Obrigada! ".

\section{Resultados}

Apresentaremos os resultados do tempo de leitura em milésimos de segundos da frase do tipo Especificidade (ESP) e esquematicidade (ESQ). Em seguida o tempo de leitura e resposta à pergunta de compreensão em milésimos de segundos e, por fim, apresentaremos o índice de acertos à pergunta de compreensão.

\subsection{Leitura da frase do tipo nível de especificidade e de esquematicidade}

O tempo médio de leitura da frase do tipo nível de especificidade e de esquematicidade por adultos jovens, por idosos saudáveis e idosos com provável Alzheimer em fase inicial e moderada estão indicados nos gráficos 1 e 2, com as respectivas análises estatísticas (ANOVA).

Quando comparamos o tempo de leitura em milésimos de segundos entre os grupos controle de adultos e de idosos e caso Alzheimer, aplicando a ANOVA, obtivemos os seguintes resultados:

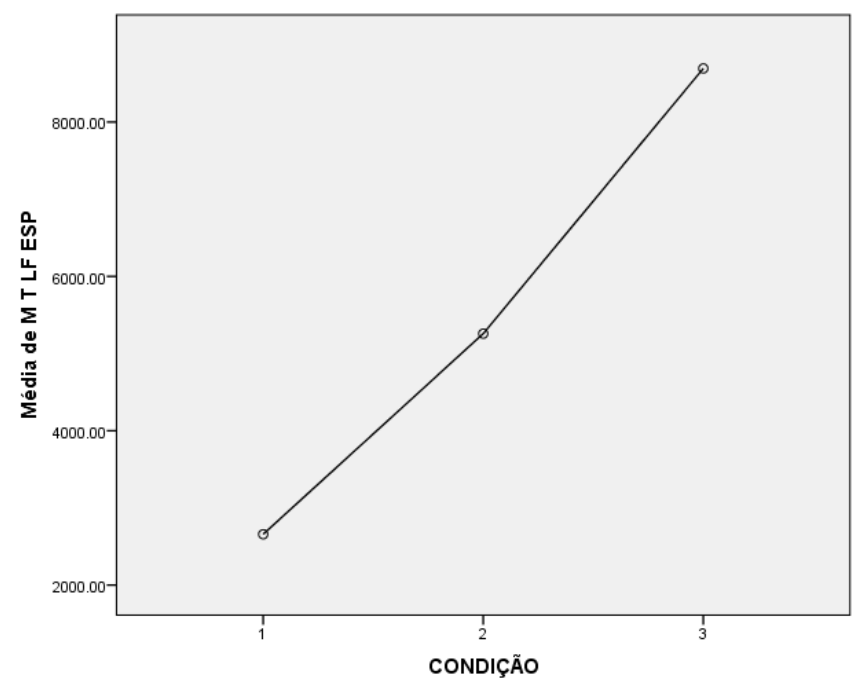

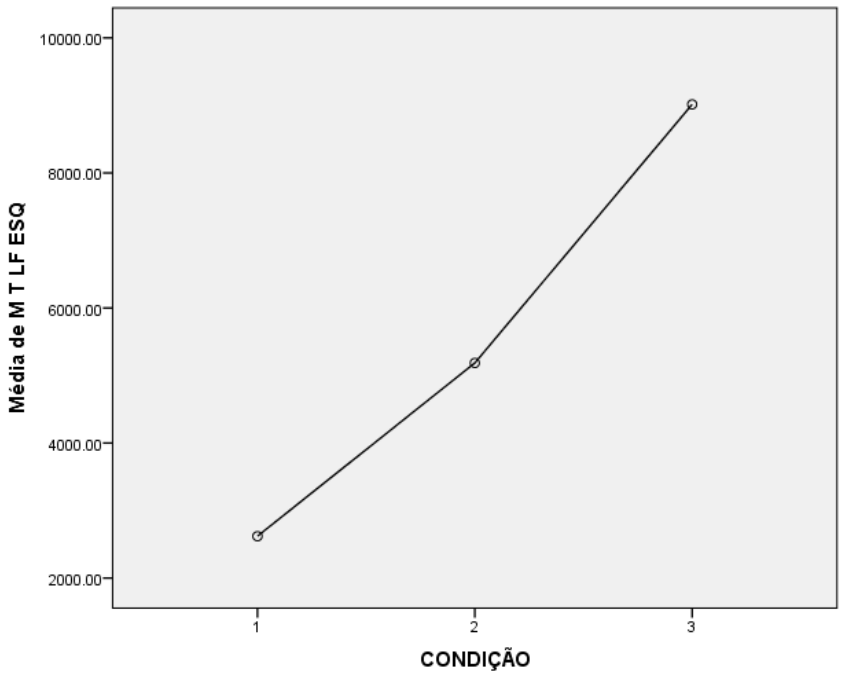

Gráfico 1e Gráfico 2: Comparação do tempo médio de leitura das frases do tipo Nível de Especificidade (NESP) e Esquematicidade (ESQ) por adultos jovens (1), idosos saudáveis (2) e idosos com provável Alzheimer em fase inicial e moderada (3).

A média do tempo de leitura de frases tanto do nível de especificidade (gráfico 1) quanto de esquematicidade (gráfico 2) é maior em idosos com provável Alzheimer em fase inicial ou moderada (IPAI/IPAM): ESP (M=8694,66) e ESQ (M=9015,32), quando comparado com a média de idosos saudáveis (IS): ESP $(M=5258,34)$ e ESQ $(M=5185,88)$ e com a média de adultos jovens (AJ): ESP $(M=2658,70)$ e ESQ $(M=2620,51)$.

Existe um efeito significativo no tempo de processamento da leitura da frase de especificidade $\mathrm{F}$ $(2,33)=168.47, p=0,000$ e de esquematicidade $F$ $(2,33)=199.55, p=0,000$.

Existe uma tendência linear significativa indicando que a média do tempo de leitura da frase de especificidade $F(1,33)=334,80, p=0,000$ e esquematicidade $F(1,33)=393,98, p=0,000$ aumenta nos idosos com provável Alzheimer em fase inicial ou moderada.

Os contrastes planejados relevaram que, no envelhecimento normal e na doença de Alzheimer, há um aumento no tempo de processamento da leitura de frases de especificidade $t(33)=15,114, p=0,000$ (unilateral) e de esquematicidade $t(33)=16,057, p=$ 0,000 (unilateral), quando comparado com adultos jovens, e que, na doença de Alzheimer, o tempo de leitura aumentou significativamente em comparação com idosos saudáveis no nível de especificidade t (33) 
$=10,417, p=0,000$ (unilateral) e de esquematicidade $t(33)=11,886, p=0,000$ (unilateral).

Considerando o tempo de leitura da frase, atestamos positivamente a hipótese de que, na doença de Alzheimer, há maior tempo para processar frases, tanto no nível de especificidade, quanto na esquematicidade, sendo o tempo de processamento maior na esquematicidade.

A frase NESP com maior tempo de processamento por idosos com provável Alzheimer foi a C21F2 "O jovem dançou um forró no baile" com a média de tempo de 10577.68 milissegundos, comparando com idosos saudáveis $(\mathrm{M}=5147.83)$ e com adultos jovens $(M=2087.32)$. Esta frase teve uma média de plausibilidade de 4.62 (em uma escala entre 1 - bastante implausível a 5 - bastante plausível).

Na frase acima destacada: "O jovem dançou um forró no baile" tem como frase controle "O jovem dançou um ritmo no baile". Observa-se que a primeira frase estabelece uma relação de especificidade em comparação com a segunda, considerando a categoria de ritmo musical "forró". A frase teve uma alta média de plausibilidade como sinalado acima e na análise da frequência da palavra forró no português brasileiro, atingiu 1762 ocorrências (180.1820227 por milhão). Importante ressaltar que a frase estava contextualizada à cultura local, os sujeitos participantes em sua grande maioria nasceram e/ou residiam no nordeste, ou seja, conhecem o forró como um dos possíveis ritmos musicais. O participante, ao se deparar com esta sentença, consegue retratar esta cena como sendo de um sujeito agente ( $O$ jovem) que exerceu uma ação (dançou) e esta era específica (forró), assim, em nenhuma hipótese, ele considerará que o jovem dançou qualquer outro ritmo musical que não o forró.

Acredita-se que, mesmo sendo uma frase contextualizada, com média alta de plausibilidade, esta possa ter tido o maior tempo de processamento dentre as 12 frases específicas do experimento devido à dificuldade de sua retenção na memória de trabalho, ou dificuldade de manter a atenção durante a leitura, visto que foi observada a estratégia de repetição da leitura da frase por mais de uma vez para melhor retêla para a próxima etapa.

A frase ESQ com maior tempo de processamento por idosos com provável Alzheimer foi a C14F1 "O homem abandonou o móvel no terreno" com a média de tempo de 10920.58 milissegundos, comparando com os idosos saudáveis $(M=5326.04) \mathrm{e}$ com adultos jovens $(M=3082.70)$. Esta frase foi a menos plausível das frases esquemáticas com a média de 3.93 (em uma escala entre 1 - bastante implausível a 5 - bastante plausível).

Esta frase "O homem abandonou o móvel no terreno" tinha como frase controle "O homem abandonou o sofá no terreno". Consideramos a primeira frase como esquemática, visto que 0 substantivo móvel, não especifica que tipo de mobília foi abandonado, podendo ser qualquer uma dentro das possibilidades de móveis existentes, do mais prototípico ao menos prototípico. A média do tempo de processamento desta frase, em comparação com a frase específica "O jovem dançou um forró no baile" é maior, provavelmente pela dificuldade de acesso aos domínios cognitivos mais esquemáticos. As categorias esquemáticas tendem a ter mais custo de processamento devido estar fora do nível básico de categorização.

\subsection{Leitura e resposta da pergunta de compreensão da frase do tipo nível de especificidade e de esquematicidade}

O tempo médio de leitura e resposta da pergunta de compreensão da frase do tipo nível de especificidade e esquematicidade por adultos jovens, por idosos saudáveis e idosos com provável Alzheimer em fase inicial e moderada estão indicados nos gráficos 3 e 4, com as respectivas análises estatísticas (ANOVA).

Quando comparamos o tempo de leitura e resposta da pergunta de compreensão da frase em milésimos de segundos, entre os grupos controle de adultos e de idosos e caso Alzheimer, aplicando a ANOVA, obtivemos os seguintes resultados: 

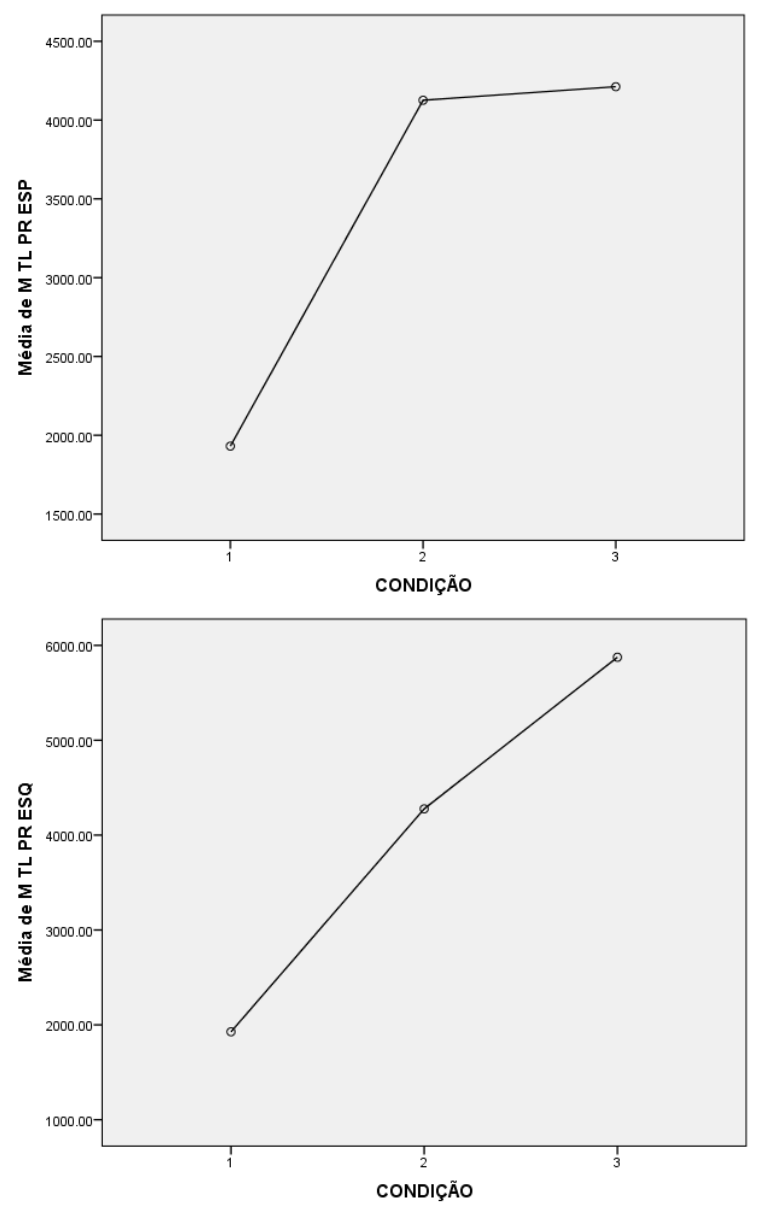

Gráfico 3 e Gráfico4: Comparação do tempo médio de leitura e resposta da pergunta de compreensão das frases do tipo Nível de Especificidade (NESP) e Esquematicidade (ESQ) por adultos jovens (1), idosos saudáveis (2) e idosos com provável Alzheimer em fase inicial ou moderada (3).

De acordo com os gráficos 3 e 4, a média do tempo de leitura e resposta da pergunta de compreensão de frases, tanto do nível de especificidade quanto de esquematicidade, é maior em idosos com provável Alzheimer em fase inicial ou moderada (IPAI/IPAM): ESP ( $M=4211,97)$ e ESQ $(M=5875,17)$, quando comparado com a média de idosos saudáveis (IS): ESP ( $M=4125,85)$ e ESQ $(M=4277,14)$ e com a média de adultos jovens (AJ): $\operatorname{ESP}(M=1931,10)$ e ESQ $(M=1926,81)$.

Existe um efeito significativo no tempo de processamento da leitura e resposta da pergunta interpretativa da frase de nível de especificidade $F$ $(2,33)=20.438, p=0,000$ e de esquematicidade $F$ $(2,33)=46.503, p=0,000$.

Existe uma tendência linear significativa indicando que a média do tempo de leitura e resposta da pergunta interpretativa da frase de nível de especificidade $F(1,33)=31,812, p=0,000$ e esquematicidade $F(1,33)=91,894, p=0,000$ aumenta nos idosos com provável Alzheimer em fase inicial ou moderada.

Os contrastes planejados relevaram que, no envelhecimento normal e na doença de Alzheimer, há um aumento no tempo de processamento da leitura e resposta da pergunta interpretativa de frases de nível de especificidade $t(33)=6,39, p=0,000$ (unilateral) e de esquematicidade $t(33)=8,89, p=0,000$ (unilateral), quando comparado com adultos jovens, e que, na doença de Alzheimer, o tempo de leitura e resposta aumentou significativamente em comparação com idosos saudáveis nas frases de esquematicidade $t(33)$ $=3,88, p=0,000$ (unilateral), porém não houve aumento significativo nas frases do nível de especificidade $\mathrm{t}(33)=0,21, \mathrm{p}=0,833$ (unilateral).

Considerando o tempo de leitura da pergunta interpretativa da frase de ESP e/ou ESQ e a escolha da resposta dentre duas opções, atestamos positivamente a hipótese de que, na doença de Alzheimer, há maior tempo para processar a esquematicidade, porém esta hipótese foi refutada no nível de especificidade.

Nas frases específicas, a pergunta de compreensão e a escolha da resposta com maior tempo de processamento obtido por idosos com provável Alzheimer foi a C9F2, da frase "O motoqueiro quebrou o espelho da moto", cuja pergunta "O que o motoqueiro quebrou da moto? "e as opções de resposta "equipamento" e "espelho" obtiveram a média de tempo de 7655.45 milissegundos, em comparação com idosos saudáveis ( $M=3389.97$ ) e com adultos jovens ( $\mathrm{M}=2115.69)$.

$\mathrm{Na}$ frase "O motoqueiro quebrou o espelho da moto", o sujeito exerce uma ação sobre um determinado objeto, no caso, o motoqueiro (sujeito), quebrou (verbo) o espelho da moto (objeto), remota uma cena especifica quando se compara com a mesma frase de forma mais esquemática " $O$ motoqueiro quebrou o equipamento da moto". Espelho é mais específico do que equipamento, visto que equipamento poderia remeter a qualquer outro objeto da moto como escapamento, pedal, dentre 
outros. A pergunta que é direcionada ao participante da pesquisa é bem clara "O que o motoqueiro quebrou na moto?", porém as duas opções de respostas poderiam ser válidas, visto que o espelho é um equipamento da moto. Contudo esta não seria a resposta mais adequada, visto que a frase especifica o tipo de objeto que foi quebrado pelo motoqueiro, portanto, espera-se como resposta "espelho".

Dentre as frases esquemáticas, a pergunta de compreensão e a escolha da resposta em que foi observado maior tempo de processamento obtido por idosos com provável Alzheimer correspondeu a C2F1, da frase "O menino levou o brinquedo na mochila", cuja pergunta "O que o menino levou na mochila? " e as opções de resposta "boneco" e "brinquedo" obtiveram a média de tempo de 9435.47 milissegundos, em comparação com idosos saudáveis ( $M=3660.93)$ e com adultos jovens ( $M=1772.46)$.

Ao contrário da frase anterior que especificava uma cena, a frase "O menino levou o brinquedo na mochila" é esquemática, visto que a categoria brinquedo tem um leque amplo de possibilidades. Quando é posta a pergunta: "O que o menino levou na mochila?" e as duas opções de resposta "brinquedo" e "boneco", ativa-se o mesmo campo semântico, porém a resposta esperada seria brinquedo, pois não é sabido pelo participante leitor da frase e pergunta que tipo de brinquedo o menino havia levado na mochila, dessa forma, marcar boneco é uma resposta que tende a ser errada.

\subsection{Acertos da frase do tipo nível de especificidade e de esquematicidade}

A média de acertos da frase do tipo nível de especificidade e de esquematicidade por adultos jovens, por idosos saudáveis e idosos com provável Alzheimer em fase inicial ou moderada estão indicados nos gráficos 5 e 6 , com as respectivas análises estatísticas (ANOVA):

Quando comparamos a média de acertos entre os grupos controle de adultos e de idosos e caso Alzheimer, aplicando a ANOVA, obtivemos os seguintes resultados:
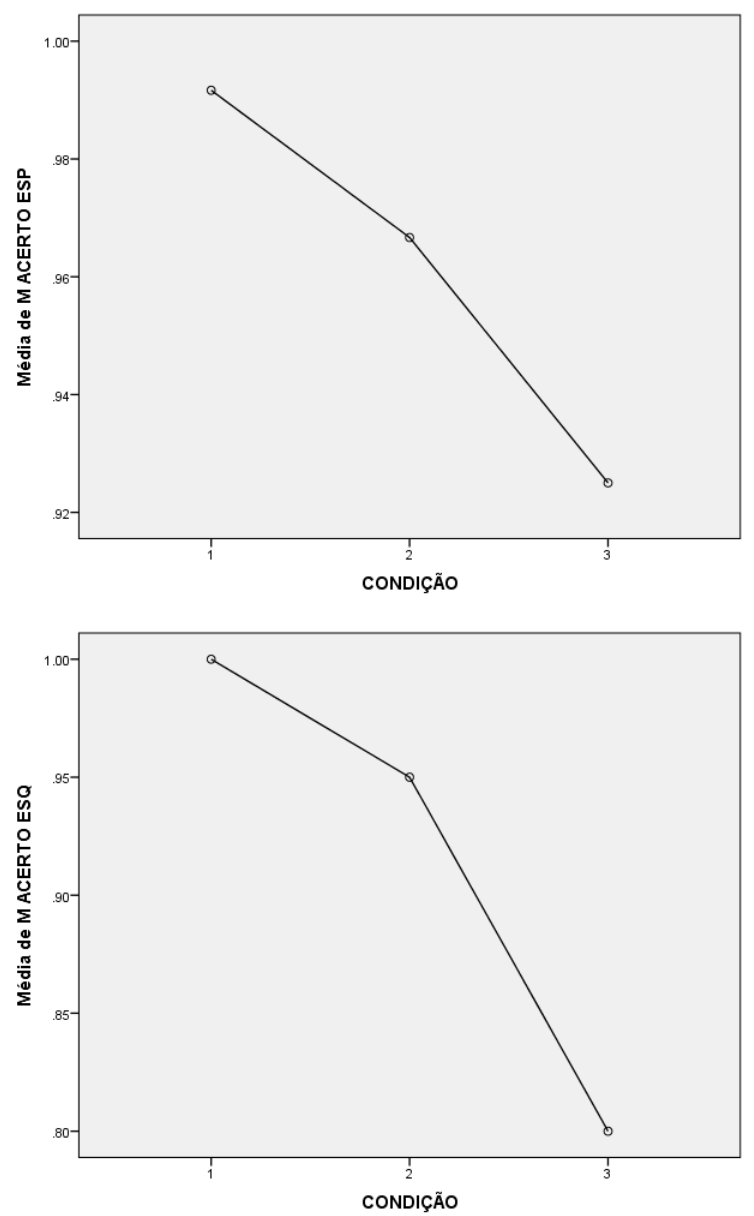

Gráfico 5 e Gráfico 6: Comparação da média de acertos das frases do tipo Nível de Especificidade (NESP) e Esquematicidade (NESQ) por adultos jovens (1), idosos saudáveis (2) e idosos com provável Alzheimer em fase inicial e moderada (3).

De acordo com os gráficos 5 e 6, a média de acerto de frases tanto do nível de especificidade quanto de esquematicidade é menor em idosos com provável Alzheimer em fase inicial e moderada (IPAI/IPAM): ESP $(\mathrm{M}=0,93)$ e ESQ $(\mathrm{M}=0,80)$, quando comparado com a média de idosos saudáveis (IS): ESP $(M=0,97)$ e ESQ $(M=0,95)$ e com a média de adultos jovens (AJ): ESP $(M=0,99)$ e ESQ $(M=1,0)$.

Existe um efeito significativo na média de acerto das frases de esquematicidade $F(2,33)=7.800, p=$ 0,002, porém não há efeito significativo na média de acerto das frases de nível especificidade $F(2,33)=$ 2.519, $\mathrm{p}=0,096$.

Existe uma tendência linear significativa indicando que a média de acerto das frases de nível de especificidade $F(1,33)=4,935, p=0,033 \mathrm{e}$ esquematicidade $F(1,33)=14,400, p=0,001$ diminui 
nos idosos com provável Alzheimer em fase inicial e moderada.

Os contrastes planejados relevaram que, no envelhecimento normal e na doença de Alzheimer, há uma diminuição de acerto de frases de nível de especificidade $t(33)=-1,763, p=0,087$ (unilateral) e de esquematicidade $t(33)=-2,739, p=0,010$ (unilateral), quando comparado com adultos jovens, e que na doença de Alzheimer a média de acertos diminuiu significativamente em comparação com idosos saudáveis nas frases de esquematicidade $t(33)$ $=-2,846, p=0,008$ (unilateral), porém não houve diminuição significativa nas frases do nível de especificidade $t(33)=-1,388, p=0,174$ (unilateral).

Considerando o índice de acerto das frases de ESP e/ou ESQ, atestamos positivamente a hipótese que na doença de Alzheimer há mais erro nas perguntas de esquematicidade, porém esta hipótese foi refutada no nível de especificidade.

A menor média de índice de acertos nas frases específicas, obtido idosos com provável Alzheimer foi a C9F2, da frase "O motoqueiro quebrou o espelho da moto" cuja pergunta "O que o motoqueiro quebrou da moto?" e as opções de resposta "equipamento" e "espelho" obtiveram a média de acerto de 0.7, comparando com idosos saudáveis $(M=1.0)$ e com adultos jovens $(M=1.0)$.

A frase específica C9F2, obteve maior tempo de processamento de leitura da pergunta e escolha das opções de resposta e também, conforme sinalizado acima, a menor média de índice de acertos. Pode-se inferir que a tomada de decisão da pessoa com provável Alzheimer entre a resposta "equipamento" e "espelho" foi equivocada em $30 \%$ dos participantes, o que pode nos levar a pensar em uma falha no acesso à memória semântica, ou uma falha na retenção da frase pela fragilidade da memória de trabalho, visto que esta pode não ter sido mantida por tempo suficiente para tomada correta da decisão.

A frase esquemática com menor média de índice de acertos por idosos com provável Alzheimer foi a C18F1, da frase "A idosa preparou um doce no micro-ondas" teve média de tempo de leitura por IPAI/IPAM ( $\mathrm{M}=8737.25)$, IS $(\mathrm{M}=5358.78)$ e $\mathrm{AJ}(\mathrm{M}=$
2657.36), cuja pergunta "O que a idosa preparou no micro-ondas?" teve a média de tempo de processamento por IPAI/IPAM ( $\mathrm{M}=6180.47)$, IS ( $\mathrm{M}=$ 5371.70) e AJ $(M=2064)$ e as opções de resposta "doce" e "bolo" obtiveram a média de acerto de 0.4, comparando com idosos saudáveis $(\mathrm{M}=0.8)$ e com adultos jovens $(\mathrm{M}=1.0)$.

Embora a frase C18F1 não tenha tido maior tempo de processamento, ela configurou a menor frequência de índice de acertos pela população com Alzheimer. As opções de resposta "bolo" e "doce" estão dentro do mesmo campo semântico, por bolo ser mais específico, pode ter sido mais facilmente ativado, visto que foi a opção de $60 \%$ dos participantes.

\section{Discussão}

Para realizar esta investigação, elaboramos um experimento psicolinguístico analisando o domínio imagético: Nível de especificidade. Por se tratar de um experimento psicolinguístico, o teste apresentou-se como uma frase, com uma pergunta e duas opções de respostas já determinadas. Porém esperava-se que, com a leitura da frase, o leitor, tendo como referência seu conhecimento de mundo, construísse o sentido e o significado do que lia, compreendesse e que escolhesse as respostas esperadas.

Concordamos com Marcuschi (2008, p.230) quando este afirma que compreender não é apenas uma ação linguística ou cognitiva "é muito mais uma ação de inserção no mundo e um modo de agir sobre o mundo na relação com o outro dentro de uma cultura e uma sociedade".

Respaldados na concepção de que a construção do significado é cognitiva e orientada pelo contexto, embasamos que só é possível compreender os possíveis e diferentes significados de uma palavra, frase e/ou discurso, devido o conhecimento enciclopédico, que é um sistema estruturado e organizado em redes (FERRARI, 2011).

Segundo a referida autora, sobre a construção do significado pelo conhecimento enciclopédico:

O fato de que se associe a construção do significado ao conhecimento enciclopédico, 
entretanto, não significa dotar uma postura de que o conhecimento associado a uma determinada palavra se estabelece de forma desorganizada e caótica. Ao contrário, a semântica cognitiva caracteriza o conhecimento enciclopédico como um sistema estruturado e organizado em rede, assumindo que os diferentes aspectos do conhecimento a que uma palavra dá acesso não têm status idêntico (FERRARI, 2011, p. 18-19).

As discussões de nossos resultados corroboram com a afirmativa de que os significados, assim como outras estruturas linguísticas, são reconhecidos como a parte de uma língua apenas na medida em que eles são enraizados na mente do indivíduo falante e quando eles são convencionais para todos os membros de uma comunidade de fala (LANGACKER, 2008).

Langacker (2008) destaca ainda que o significado de uma frase não é apreendido instantaneamente, ele ocorre em um espaço de tempo que é processado mentalmente pelo leitor, considerando seu conhecimento de mundo, de forma que frases semanticamente equivalentes são conceptualizadas através de um tempo em milissegundos, podendo resultar em diferentes experiências mentais e diferentes significados linguísticos.

Estamos diante de um estudo pioneiro, que buscou investigar como ocorre o processamento da imagética convencional em idosos com Alzheimer, fazendo uso de experimentos com leitura automonitorada. Não localizamos na literatura nacional e internacional experimentos similares para confrontar nossos resultados. Nossos resultados por sua vez, nos permitiram ter indícios de como ocorre este processamento, não só na população idosa e de adultos jovens, como na população com Alzheimer conforme discutiremos a seguir.

Este experimento tinha como objetivo identificar se, na doença de Alzheimer, existe comprometimento na compreensão da imagética convencional de frases gramaticais no nível de especificidade, por meio da técnica de leitura automonitorada. Formulou-se a hipótese que a pessoa com Alzheimer tem processamento mais lento na leitura das frases e na escolha da resposta e tem índices de acerto nas perguntas de compreensão inferior ao grupo controle.

Considerando o tempo de leitura da frase, demonstramos que, na doença de Alzheimer, há maior tempo para processar frases, tanto no nível de especificidade, quanto o de esquematicidade, sendo o tempo de processamento maior na esquematicidade. Quando foi analisado o tempo de leitura da pergunta de compreensão da frase de ESP e/ou ESQ e a escolha da resposta dentre duas opções, atestamos positivamente a hipótese que na doença de Alzheimer há maior tempo para processar a esquematicidade, porém esta hipótese foi refutada no nível de especificidade. Esses resultados encontram argumentos na teoria da Categorização $(\mathrm{ROSCH}$, 1973, 1975).

Os resultados apresentados pelos idosos com provável Alzheimer nos remetem ao processo de categorização humana. Categorizamos em nível hierárquico, tendo um nível básico onde grande parte de nosso conhecimento é organizado, partindo para um nível mais esquemático/sobreordenado ou para um nível mais subordinado/específico (ROSCH; MERVIS, 1975).

Corroboramos com o pensamento de Rizzatti, (2001), quando refere que a categoria básica:

É o nível mais inclusivo de categoria em que as formas dos objetos são parecidas e, consequentemente, mais facilmente reconhecidas; é também o nível privilegiado no desenvolvimento linguístico: o primeiro a ser nomeado, aprendido e a entrar no léxico da língua. Neste nível uma única imagem mental pode refletir a categoria inteira (RIZZATTI, 2001, p.18).

A categorização é importante para a construção do significado de uma determinada cena, como por exemplo, para o participante compreender que "O jovem dançou forró no baile”, há registros na memória de longo prazo de que forró é um ritmo musical predominante no nordeste, dançado por pessoas em diversas faixas etárias, porém, favorito entre os jovens. Portanto, ao deparar-se com esta frase, domínios e categorias de ritmos musicais são acionados na memória semântica, o que faz compreender o seu significado, distinguindo-a de uma frase que remeteria 
a outro significado, tipo: "O jovem dançou um samba no baile". Samba e forró são ritmos musicais, mas sabe-se que o significado construído mentalmente para a cena de dançar um forró é diferente da cena construída para dançar um samba.

No mesmo contexto, o maior tempo de processamento em categorias mais esquemáticas pode remeter a uma dificuldade de acesso aos domínios cognitivos no nível mais sobreordenado, no caso da frase "O homem abandonou o móvel no terreno", a categoria móvel é mais esquemática, está fora do nível, básico, assim o idoso com Alzheimer processa esta cena de forma mais lenta, há mais dificuldade no acesso da categoria em comparação com idosos saudáveis. O maior tempo de processamento de escolha da resposta correta pode remeter também a um prejuízo na memória de trabalho, visto que esta já se encontra comprometida na fase inicial da manifestação da doença (BELLEVILLE, PERETZ E MALENFANT, 1996).

$\mathrm{Na}$ variável dependente, índice de acerto das frases de ESP e/ou ESQ, atestamos positivamente a hipótese que na doença de Alzheimer há mais erro nas perguntas de esquematicidade, porém esta hipótese foi refutada no nível de especificidade.

Este resultado confirma a hipótese de que há mais dificuldade de acessar a partir de categorias básicas, categorias mais esquemáticas ou mais específicas, porém, percebe-se que há um pior desempenho no acesso às categorias mais esquemáticas por pessoas com provável Alzheimer, o que nos leva a inferir que estas são categorias mais custosas no processamento, ou porque ocorre um apagamento de certas categorias cognitivas devido à deterioração da memória semântica (GROSSMAN, ET. AL., 2003) ou porque, devido à pouca frequência no uso da frase no contexto diário, há uma dificuldade de acessar determinadas categorias mais esquemáticas ou de mantê-las na memória de trabalho por tempo suficiente para tomada correta de decisão.

\section{Conclusão}

Diante dos resultados previamente apresentados, esta investigação respondeu as perguntas norteadoras, atingiu seus objetivos $e$ confirmou a hipótese de que a compreensão da imagética convencional em frases gramaticais, no nível de especificidade, está afetada desde os estágios iniciais da doença de Alzheimer, devido ao declínio cognitivo progressivo.

Analisamos a compreensão do nível de especificidade entre idosos com e sem Alzheimer e identificamos que as pessoas com Alzheimer demandam maior tempo de processamento na leitura de frases, tanto na especificidade quanto na esquematicidade, sendo maior o tempo nesta. E que há mais erro nas perguntas de esquematicidade, porém esta hipótese foi refutada na especificidade. Identificamos que a memória de trabalho, a velocidade de processamento, a tomada de decisão e a orientação temporal são os aspectos cognitivos mais afetados para a compreensão desta imagética convencional, devido ao declínio cognitivo progressivo decorrente da doença de Alzheimer.

\section{Referências}

BELLEVILLE, S; PERETZ, I; MALENFANT, D. Examination of the working memory components in normal aging and in dementia of the Alzheimer type. Neuropsychologia, 34 (3), 1996. p. 195-207.

FERRARI, Lilian. Introdução à Linguística Cognitiva. Editora Contexto. São Paulo, 2011. 171 p.

GROSSMAN, M., ET. AL. Neural basic for semantic memory difficulty in Alzheimer's disease: an fMRI study. Brain, 126, 2003. p. 292-311.

LAKOFF, George. Women, fire, and dangerous things: what categories reveal about the mind. Chicago: The University of Chicago Press, 1987.

LANGACKER, R. W. Cognitive Grammar. A basic Introduction. Oxford University Press, 2008.

LEITÃO, Márcio. Psicolingüística Experimental: Focalizando o processamento da linguagem. In: Martelotta, M. (org.) Manual de Lingüística. São Paulo: Contexto. 2008. 
LIMA, G. A. B. O. Modelos de categorização: apresentando o modelo clássico e o modelo de protótipos. Perspectivas em Ciência da Informação, v. 15, n. 2, 2010. p. 108-122.

MARCUSCHI, L. A. Produção textual, análise de gêneros e compreensão. São Paulo: Parábola Editorial, 2008.

ROBLES, AMON \& PEÑA-CASANOVA. Evaluación neuropsicológica y funcional de la demência. Barcelona: JR Prous, 2002. p. 9-48.

RINALDI, J.; SILVEIRA, M.; KOCHHANN, R.; PARENTE, M. A. M. P.. A compreensão de leitura textual como um instrumento de diagnóstico de pacientes com demência de Alzheimer leve e moderado. Estudo Interdisciplinar Envelhecimento. Porto Alegre, v. 13, n. 1, 2008. p. 117-132.
RIZZATTI, C. L. Da teoria prototípica da categorização de Rosch à teoria de protótipos de Kleiber. Revista Língua \& Literatura, 2001.

$\mathrm{ROSCH}$, Eleanor. On the internal structure of perceptual and semantic categories. In: MORE, T.E. Cognitive Development and the Acquisition of Language. New York, Academic Press, 1973. p. 111-144.

Cognitive representations of semantic categories. Journal of Experimental Psychology: General, 104, 1975. p. 192-233.

ROSCH, E. \& MERVIS, C.B. Family Resemblances: studies in the internal structures of categories. Cognitive Psychology, 7, n. 4, 1975. p. 573-605.

SILVA, Augusto Soares. Perspectivação conceptual e gramática. Revista Portuguesa de Humanidades/ Estudos Linguísticos. Faculdade de Filosofia da U.C.P. Braga. Vol, 12-1. 2008.

\section{COMO CITAR ESSE ARTIGO}

MORAES, Berla Moreira de; LEITE, Jan Edson Rodrigues. Compreensão de frases gramaticais com nível de especificidade e esquematicidade por pessoas com Alzheimer: uma análise psicolinguística e cognitiva. Signo, Santa Cruz do Sul, v. 41, n. 71, set. 2016. ISSN 1982-2014. Disponível em: <https://online.unisc.br/seer/index.php/signo/article/view/7217>. Acesso em: __ 2016. doi: http://dx.doi.org/10.17058/signo.v41i71.7217. 